Encrucijada/Crossroads: An Online Academic Journal

Issue 1, Volume 12003

\title{
Dominican Immigrants and Social Capital in New York City: A Case Study
}

\author{
Julissa Reynoso \\ Legal Professional and Political Activist \\ Alumnus of Harvard University and Columbia Law School
}

\section{Introduction}

The textbook (Putnam 1995) depiction of a public realm separated from private life, in which people of good will are engaged in dispassionate, rational deliberation of civic engagement, is being questioned by policy-makers and academics, alike. The claim is that Americans are no longer joining groups and associations and, hence, social capital and trust formation has been on the decrease. With the growing diversity of the United States population, it is important to examine how trust and social capital can be affected by contextual factors such as race and ethnicity.

The aim of this study is to demonstrate that new forms of social capital are being invented out of the buzzing confusion of modern American life. The investigation integrates some of the ways in which social capital is created by an immigrant community. In this particular case, immigrant social capital in the form of informal and formal associations and networks are observed. The case of Dominican immigrants in New York City and their experience in generating transnational social capital is presented. The argument is that social capital in itself is crucial for adaptation but is not enough to generate an immigrant group's economic sustainability in the United States. The premise is that adaptation to a foreign society is a complex process depending not only upon individual motivation and abilities but also upon specific contexts of reception (Portes and Rumbaut 1990). Preexisting ethnic communities represent the most immediate context of reception, serving as the basis of a unique social capital to facilitate immigrant adaptation.

Three definitions are essential to this analysis. First, "social capital," as defined by Robert Putnam (1993, 167), is "trust, norms and networks' that facilitate social co-ordination for mutual benefit." Putnam hypothesizes that trust and informal institutions (networks, norms, conventions, unwritten codes of behavior) explain the prospects for establishing and consolidating democracy and successful capitalist development. Second, 'trust' can be designated as a set of expectations shared by all those involved in the exchange and "anticipated cooperation" (Burt 1997, 339) created by repeated interaction. Finally, "immigrant culture" is defined as the "original" culture of a group, consisting of 
an entire way of life, including, ideas, beliefs, values, behavioral patterns, and all that immigrants bring with them when they arrive in their new country.

The effect of immigrant culture depends on the micro-social structures on which ethnicity is based, as well as on the macro-social structures of the larger society. The following analysis attempts to show that "the dense set of associations" (Coleman 1990, 316) provided by the immigrant community can offer a system of supports that promote advantageous action. The community is not simply the sum of isolated families, but is contained within a set of structural limits maintained within the group as well as imposed from outside. Thus, an explanation of differential patterns of adaptation must take into account the normative qualities of immigrant communities and the patterns of socio-economic relations surrounding these communities.

In analyzing the case of social capital in immigrant communities, the notions of "North" and "South" in Development Studies, in particular, and the social sciences, in general, are reevaluated. In a world with few borders and boundless migration such absolute terms are antiquated and ineffectual. In this study, the North becomes the South.

The sources to complete this investigation are located primarily in the United States. I spent a month and a half gathering data from the Dominican Studies Institute at the City University of New York, the City University of New York Library, and the Saguaro Seminar on Social Capital Center at Harvard University, Massachusetts. All interviews and surveys were conducted in New York City.

\section{Socio-economic Profile of Dominican Immigrants}

Since the reform in U.S. immigration laws in 1965, Dominicans have constituted an important component of the flux of "new immigrants" to the United States. The surge in the number of Dominicans, principally in the great urban center of New York (See Table I), has created what constitutes new ethnic and multi-ethnic communities. The growth of this immigrant community and the character of their socialization and politicization is of great importance both to the Dominican and North American communities. It constitutes a new ingredient to American democracy.

At the dawn of the 1990s, international migration has become an established feature of the Dominican society and economy. Initially, the politically motivated outburst of U.S.-bound emigration in the 1960s affected just a few Dominican regions and social groups-most particularly, segments of the rural and urban lower-middle classes, as well as left-leaning political activists in the Cibao region of the country and Santo Domingo, the capital city (Hendricks 1974, 24-29). Yet, a sharply deteriorating economic situation in the Dominican Republic in the 1980s and early 1990s greatly affected the massive emigration of

Encrucijada/Crossroads 1.1 (2003): 57-78 
Dominicans to the U.S. during the last decade. To date not a single region or segment of Dominican society has not felt, directly or indirectly, the effects of international migration.

\begin{tabular}{|l|l|l|}
\hline \multicolumn{2}{|l|}{ Table I: The Dominican Population in the U. S. and New York City } \\
\hline & 1990 Number & 1997 Number \\
\hline United States & 520,121 & 832,000 \\
New York City & 332,713 & 495,000 \\
Outside New York City & 187,408 & 337,000 \\
$\%$ in New York City & $64.0 \%$ & $59.5 \%$ \\
\hline
\end{tabular}

Source: March 1996, 1997 CPS; 1990 U. S. Census of Population

The real number of Dominicans residing in the United States is not easily calculated (Bray 1987, 152). At least $10 \%$ of the Dominican population -- 8 million in total-currently lives in the United States. Current estimates on the population oscillate between 800,000 and 1,000,000. Estimates based on the 1996 and 1997 Current Population Survey demonstrated in Table I indicate that there were 832,000 Dominicans residing in the United States in 1997. This constitutes a substantial increase over the 520,121 Dominicans counted by the 1990 Census of Population. The variation in estimates is due to the lack of research on the number of undocumented immigrants.

For the past three decades, emigration from the Dominican Republic, especially to New York, has grown steadily. ${ }^{1}$ By the 1970s the Dominican Republic had become the top foreign supplier of immigrants to New York (Youssef 1982, 66). Immigrant islanders have concentrated mostly in New York City, where according to the 1990 U.S. Census, about 7 of every 10 Dominicans in the continental United States reside (Guarnizo 1994, 71). As Table I shows, close to half a million Dominicans resided in New York City in March 1997. Behind Mexicans and Cubans, Dominicans constitute the largest number of Latin American immigrants in the U.S. In the last decades, Dominicans compose the largest number of foreigners registered in New York City by the Immigration and Naturalization Service (INS). They constitute, behind the Puerto Ricans, the second largest Latino population in New York.

Demographically, according to a survey conducted by Pessar $(1987,97)$, women migrants outnumber men, with females comprising 60.4 percent of the immigrant population surveyed. The average age at arrival for women was 22.2 years and the median level of education was 8.0 years. Of the women, 91.5 percent had worked for pay at some time since moving to the United States. As for men, their average age at arrival was 22, and the median level of education was 9.4 years. Similar to the women, 91.3 percent had worked for wages at some time during their residence in the United States. More recent surveys indicate the 
average age rose to 28 years in 1990. By comparison, the average age of New Yorkers in 1990 was 36 years (Hernández and Rivera-Batiz 1997, 38).

Dominicans, unlike other major Latino groups, tend to be more concentrated residing exclusively in barrios or ghettos like Washington HeightsInwood (See Table II), home to 59\% of Dominicans registered by the INS. Other areas of Dominican concentration include sections of the Upper West Side and Lower East Side of Manhattan, the South Bronx, and Corona-Jackson Heights in Queens. Table II decomposes Dominican New Yorkers according to borough of residence. The largest concentration occurs in Manhattan, where 41.1 percent of the Dominican population resides.

\begin{tabular}{|l|l|l|}
\hline \multicolumn{2}{|l|}{ Table II The Dominican Population in New York City By Borough } \\
\hline New York City Borough & Number 1990 & $\%$ of Total Dominican Pop., 1990 \\
\hline Manhattan & 136,696 & $41.1 \%$ \\
The Bronx & 87,261 & 26.2 \\
Brooklyn & 55,301 & 16.6 \\
Queens & 52,309 & 15.7 \\
Staten Island & 1,146 & 0.4 \\
\hline Total & 332,713 & 100.0 \\
\hline
\end{tabular}

Source: New York City Department of City Planning, Socio-economic Profiles, City of New York, March 1993.

The definition of the economic and social characteristics of Dominican immigrants has been an issue of debate. The Dominican migration flux has been characterized as predominantly "middle class" (Bray 1987), as low-middle and urban proletariat (Báez and D'Oleo Ramírez 1986), or as diverse, with a proportional representation from all sectors, with the exception of the most qualified professionals and least qualified laborers (Garrison and Weiss 1987, 235-54). Garrison and Weiss conclude that the Dominican community is largely working-class of origin as well as occupation. Further, several field studies in the Dominican Republic have reported that the main source of U.S.-bound migration is the established urban working class possessing some skills and resources, rather than the poorest rural strata. Grasmuck and Pessar $(1991,95)$ observe:

Contrary to popular belief, labor exports have not drawn heavily from the large pool of marginalized workers. It is not the unemployed themselves, but the relatively skilled and educated, whose wages and security are threatened indirectly by the existence of a large reserve of labor who choose to migrate. The migrants are workers who, precisely because of their relatively advantageous position, were able to finance the expensive move to the United States.

Encrucijada/Crossroads 1.1 (2003): 57-78 
Indeed, the U.S.-bound Dominican migrants can no longer be considered a homogeneous group of poor, uneducated people who remain so upon immigration. Available census, survey, and ethnographic information, for example, show the presence of highly educated people among Dominican migrants, at levels higher than among non-migrants. Although the presence of well-educated people among Dominicans is not new, their numbers have been growing steadily, especially during the last decade. According to some estimates, between 1986 and 1991 alone, about 15,000 Dominican professionals entered the United States, some 10,000 of them undocumented migrants (Guarnizo 1994, 73).

The wealth of educated Dominican immigrants, however, has not resulted in economic prosperity for the community. Dominicans are considered one of the poorest immigrant groups in New York City. A study conducted by the City College of New York's Dominican Studies Institute found that the unemployment rate of Dominican men and women in New York City approximated 18 percent in 1996; these figures are more than twice those for the overall population of New York City whose employment rate hovered between 8 and 10 percent in 1996 (Hernández and Rivera-Bátiz 1997, 62). The study concludes:

The collapse of economic activity in the City between 1989 and 1992 and the sluggish recovery since that time has impacted the Dominican population in a sharply negative way. In particular, the comparatively low, and declining earnings of unskilled workers in New York constitute a formidable barrier for the Dominican population. (64)

Table III displays the average annual household income of various groups of New Yorkers in 1996.

\begin{tabular}{|l|l|}
\hline Table III: The Income of Dominican Households in New York City \\
\hline Dominican Population & Mean Household Income, 1996 \\
New York City Average & $\$ 23,668$ \\
Non-Hispanic White Population & 53,348 \\
Non-Hispanic Black Population & 77,949 \\
Hispanic Population, Overall & 34,772 \\
\hline
\end{tabular}

Source: March 1997, Current Population Survey

New York's economic recession led many Dominicans to seek alternative economic paths. The increase in the number of Dominicans concentrated in certain barrios has allowed for facility in the rise of the informal sector. In addition to working regular hours, men, for example, sell lottery tickets on the side, drive "gypsy" cabs, make repairs for neighbors, or work in bodegas (small, walk-in stores that stock food specialties of the Hispanic Caribbean) on weekends. 
Women bake cakes, sew clothing, serve as hairdressers, take care of children, sell cosmetics and clothing, or work as domestics. Families also often rent out rooms in their apartment for extra income. Although toiling in dead-end, low-paid jobs in the secondary labor market remains the most common path of economic survival, particularly in metropolitan New York, it also yields alternative paths of economic incorporation and, hence, class restructuring (Guarnizo 1994, 73). Furthermore, deprived by licensing barriers of the possibility of practicing their professions, many educated Dominicans have turned to small businesses as a means for economic subsistence and mobility. For start up capital, they have used a variety of sources, ranging from personal savings to laundered profits from the drug trade. All these mechanisms generate income that is not easily estimated and, hence, not reported.

\section{The Ethnic Response: An Informal Survey}

This section's objectives are to further describe the Dominican population and their "civic engagement" potential in New York City via an updated, informal survey. Fieldwork tested the basic proposition that Dominican immigrants define the variables of social capitalists according to the Putnam model $(1993,180)$, which states:

Social trust, norms of reciprocity, networks of civic engagement, and successful cooperation are mutually reinforcing. Effective collaborative institutions require interpersonal skills and trust, but these skills and that trust are also inculcated and reinforced by organized collaboration.

The site for this study was New York City. The survey was conducted in the boroughs of Manhattan, specifically the neighborhoods of Harlem and Washington Heights, and the Bronx, specifically the neighborhood of the South Bronx. Questionnaires were distributed in both English and Spanish, according to the most familiar language of the individual sampled. The survey contained demographic characteristics specific to the Dominican experience.

The survey took a random sample of 148 participants. All were either Dominican immigrants (83 percent) or U.S. born Dominican-Americans (17 percent). Of the immigrants sampled, 51 percent reported "economic opportunities" as the primary reason for immigrating; "joining relatives" followed with 39 percent; "educational opportunities" was last with 10 percent. More than half of the sampled (57 percent) were American citizens. Of the participants 75 percent were female, 25 percent male. The average age of the sample was 28 years and ages ranged from 16 to 62 years old. All resided in New York City with 58 percent living in Manhattan, 35 percent in the Bronx, and 7 percent in

Encrucijada/Crossroads 1.1 (2003): 57-78 
other boroughs. Of the sampled, 77 percent declared they visited the Dominican Republic at least once per year.

When asked to classify themselves ethnically, half of the participants claimed to be "Dominican" before anything else. Of the rest, 30 percent claimed Hispanic/Latino first; 7 percent choose "Dominican-American," and 13 percent both "Hispanic/Latino" and "Dominican." From those choosing "Dominican," the average age was 33 and 90 percent were immigrant. From those choosing "Hispanic/Latino," the average age was 24 years and 73 percent were immigrants. The average age of those who chose "Dominican-American" was 22 years and 50 percent were immigrants. Finally, the average age of the dual choice of "Hispanic/Latino" and "Dominican" was 26 years and all were immigrants.

In terms of per-capita household income and level of education, the findings were similar to those reported by earlier surveys on the community. Of the pooled, 50 percent made less than $\$ 12,000$ per year, well below the New York City average of $\$ 19,000$; 9 percent made between $\$ 12,000$ and $\$ 24,000$ per year; 28 percent earned between $\$ 24,000$ and $\$ 36,000$ per year; 11 percent made between $\$ 36,000$ or more per year. With regard to years of education, 10 percent had less than a high school education; 49 percent had completed high school; 10 percent had some university or technical training; 24 percent had finished university; 7 percent had received some form of post-graduate education.

In order to assess "trust," individuals were surveyed about informal borrowing and lending of capital. Of those sampled, 30 percent had borrowed money from some individual in the past year. When asked if those lending were relatives, answers varied: 27 percent claimed all were relatives; 40 percent claimed some; and 33 percent declared none were relatives. With regard to lending money, 46 percent had lent money to some individual in the past year; of those, 25 percent claimed all borrowers were relatives and 50 percent declared only some to be relatives with the remaining declaring no relation. Finally, those who had young children -- 30 percent of the sample-were asked about childcare when either parent was not present; 60 percent claimed a relative took care of the child (either a grandmother or aunt) while the rest choose 'other' and specified neighbors as the primary source of child care.

Using several Putnam variables, the sample tested positively for "civic engagement." Of the pooled, 85 percent claimed to belong to some form of formal organization or group. Of those claiming to belong to formal groups, 31 percent belonged to 'educational' organizations; 27 percent to 'socio-cultural' groups; 21 percent to 'religious' organizations with the remaining 20 percent belonging to sport and/or professional organizations. While 33 percent almost never attended religious services, the rest claimed to attend religious services at least once per month with 46 percent attending three or more times per month. With respect to newspaper readership, 82 percent of those sampled claimed to 
read the newspaper at least once or twice a week with 38 percent reading it more than three times per week. The language of choice in newspaper readership was split with 51 percent reading predominantly the English news and the rest reading predominantly the Spanish.

\section{Dominican Social Capital}

Concurrent with these overview observations and data, the current development of Dominican social capital and the potential of networks and associations in the context of socio-political processes at the community level is analyzed. Dominican prominence stems not only from their sheer numbers and spatial concentration but also from their notable entrepreneurial drive and increasing clout in the local political power structure that can be attributed to the emergence of community social capital. Throughout this work, the extent to which immigrant Dominicans possess "social capital" and organization/association-building qualities and how these influence their socialization and politicization in the United States, particularly New York City is evaluated.

The term "social capital" is used here to mean a wealth of intangible social resources-such as information, social support, and personal connections - indispensable for achieving social, economic, and political goals. According to Bourdieu and Wacquant (1992, 119): "Social capital is the sum of resources, actual or virtual, that accrue to an individual or a group by virtue of possessing a durable network or more or less institutionalized relationships of mutual acquaintance and recognition." Social capital refers to potential value that inheres in social relationships between people. "Ethnic social capital" refers to cases where social capital is bound by an ethnic, immigrant culture. The Dominican case presents such social capital formation.

Existing studies on Dominican migration and immigration, in general, have produced a wealth of knowledge about the consequences of migration for the societies involved, especially in the economic realm. However, they have neglected the socio-cultural transformations, and their implications, experienced by migrants themselves. Such transformations have been especially accelerated by the rapid global industrial, technological, and socio-political changes undergone in the last two decades. Indeed, global restructuring has altered the socio-economic contexts in which migrants' actions are embedded. Existing studies have overlooked the way that the interaction between contextual changes and the social recomposition of the migrant population has resulted in new social arrangements, associations and relations, and others weakened or lost, while new ones are being forged. It is important to look at Dominican migrants as a flow of people moving from one nation-state to another and conceptualize them as a distinct social group emerging from the intricate web of political, economic,

Encrucijada/Crossroads 1.1 (2003): 57-78 
social, and cultural forces emanating from the particular migration experience of U.S.-bound Dominicans.

Indeed, the dominance of New York City for Dominicans and the near absence of migrants in geographically closer and less frigid U.S. cities attest to the significance of social and associational forces in guiding these flows (Portes and Grosfoguel 1994, 60). For the most part, it is kinship that links the members of the chain migration. Although U.S. immigration law favors "family reunification," the definition of the "family" in immigration legislation does not reflect the extended network of cooperating kin who constitute the practical and moral "family" of most Dominicans (Garrison and Weiss 1979, 264-83). For most Dominicans, the "true family" extends far beyond those boundaries to include married children, parents, and siblings. The result is that extralegal and illegal migration practices are often used to reunite the socially and culturally meaningful Dominican family.

The $\operatorname{Vargas}^{2}$ family serves as an example of this migration chain. Julio Vargas arrived as an illegal in the United States in 1974 leaving his wife and child in the Dominican Republic. Mr. Vargas crossed the Mexican border with a group of other Dominicans who had bought the services of an expert in viajes por la izquierda (trips via the left). Dolores Vargas, using someone else's U.S. Residence Card, joined her husband in 1978. Mrs. Vargas filed for permanent residency and received her U.S. Residence Card in 1981 and, subsequently, brought her daughter into the U.S. as her dependent in 1982. Mrs. Vargas went on to petition for her father's and siblings' visas; Mrs. Vargas's father and seven siblings arrived in New York City in 1992. Mrs. Vargas's siblings, in turn, have brought eight of their children to the United States using the dependent child petition, and have their spouses and other children on the way. In addition, Mrs. Vargas married her cousin for visa purposes and he, too, received a visa to migrate. Cumulatively, Mr. Vargas's initial migration has resulted in the migration of 19 other individuals in the time frame of twenty-four years.

Dominican formal networks and associations within the United States have taken longer to forge. Dominican activists began to mobilize themselves in the early 1980s seeking greater participation in North American politics. Programs specifically designated to politicize the inner-city poor predominantly were discontinued in the 1970s. In the new climate of fiscal austerity, "self-help" groups within Dominican communities became one of the few options for new immigrant groups. ${ }^{3}$ In the last decade, Dominicans have created formal voluntary associations of ethnic composition that have helped breach the gap between the immigrant community and North American society. These organizations take on a variety of causes and objectives. Political loyalty, in particular, constitutes one of the most influential factors in organizing, for Dominicans in New York maintain a strong interest in Dominican domestic politics. The circular migration- 
trend has contributed to the reinforcement of ties with the society of origin, as with its social symbolism. All these contribute to the evolution of a unifying bridge between New York and the island. Moreover, the association building has raised levels of participation at all levels of community institutions. Indeed, this social capital formation has created a form of support-network apparatus that has contributed to the influx in migration. This has dramatic effects on the sociopolitical evolution of Dominicans as an ethnic group in the United States.

Clearly, the longer Dominicans reside in New York City, the greater are the possibilities they will organize and create autonomous institutions. Although Dominican immigration began to "take off" in 1961, and the first ethnic organization appeared in 1962, Georges $(1984,6)$ found fewer than a dozen associations were formed by 1971. In contrast, Sassen-Koob (1987, 283) identified 36 Dominican formal associations on the Upper West Side alone in 1978; by 1984 there were about 90 in the area, and a total of about 125 in the city as a whole. The fact that 81 percent of Dominicans interviewed in 1984 by Georges $(1987,299)$ had joined or formed associations only after 5 or more years of residence in the City, and 26 percent joined after 10 or more year, suggests that the proliferation of immigrant associations may reflect adjustment in the receiving society rather than serve as a means to achieving that adjustment.

The early associations created in the mid-1960s included professionals, business men and consular officials-Dominicans who had more ties to other Hispanic middle-class persons in New York than to working-class Dominicans. These associations - many of which are still active-were restrictive with respect to social class and political orientation, and their objectives were and continue to represent a class-based view of Dominican society and culture. Further, this small, but focal element of mainly political exiles and dissidents reorganized their Dominican parties in New York and mobilized grass-roots associations to oppose the regime of then Dominican president Joaquín Balaguer.

Changing conditions in New York City, the rapid deterioration of the economic and political conditions in the Dominican Republic, and changes in the social composition of the migrant population generated a growth in social capital, and, consequently, a turnaround in Dominicans' political stand vis-à-vis the two societies. As a result, Dominicans gained positions in New York City's school boards, followed by their entry into the city's broader political arena. Moreover, migrant organizations and associations, especially business organizations, have actively lobbied for legislation favoring migrants.

During the 1980s a foundation for future political mobilization was laid in the flowering of Dominican associations, social clubs and self-help organizations, culminating in the formation by 1984 of two federations of associations: the Association of Clubs and the Dominican Day Parade Committee (Georges 1987, 299-301). The Dominican Day Parade Committee lobbied to distinguish the

Encrucijada/Crossroads 1.1 (2003): 57-78 
Dominican presence in city and state government; in the past Dominicans were often grouped with Puerto Ricans, a group that itself has been under-represented in local and state politics (Georges 1989, 198). The Committee's successful arrangement of the Dominican Day Parade in the early 1980s was followed by a successful lobby to declare a "Dominican Week," and other similar activities in order to win symbolic acknowledgement.

The Dominican Political Front was created explicitly for political reasons and sought to mobilize and unify the Dominican electorate, selecting potential Dominican leaders and preparing them as candidates for local and state elections. In response to the low level of representation of Dominicans in the political institutions of Washington Heights, this organization organized from within local political clubs the promotion and selection of candidates. An article published in the Uptown Dispatch, 13-26 September 1985, reported that in 1985, the Dominican Political Front successfully organized Dominican voters to elect a Dominican candidate as Leader of the District 71 Assembly in Washington Heights.

In addition to these larger organizations, smaller groups have sprung up targeting specific dimensions of the Dominican experience. The Dominican Women's Caucus in New York caters to professional Dominican women and promotes the development of the girl-child in educational and professional environments. According to a board member of this organization, "We seek to provide students, in particular girls, with the necessary tools to compete locally and globally."4 Organizations like La Unión de Jóvenes Dominicanos (The Dominican Youth Union) based in the City College of New York was formed in 1987 and is responsible for politicizing a large segment of the Dominican youth in the City University of New York system against education funding cuts and police harassment. In addition, in recent years more "elite" schools like Harvard and Columbia University have created their own Dominican students' associations leading to the creation of the Dominican-American Professional Alliance (DAPA) and the Dominicans 2000 Project.

Today, Dominicans who join ethnic associations come from all sectors of Dominican society. In fact, the urban/rural origins of association members are nearly identical to origins of the total sample population of Dominicans in New York: 60 percent of association members were born in the four largest cities of the Dominican Republic, compared to 61 percent of the total sample population, while only 20 percent of association members were born in villages or towns with populations of less than 10,000 (Gurak 1982).

Dominican migration proves that demographic concentration in New York City matters. Washington Heights stretching north on the west side of upper Manhattan has provided a platform and inspiration for forms of political organizing and activism among Dominicans. One noteworthy effort involved a 
struggle for greater community control over the schools in northern Manhattan's Community School District 6. Of the 25,000 students attending elementary and intermediate schools in this district during the late 1980s, more than 80 percent were Dominican (Linares 1989, 78). At that time their schools were the most overcrowded in the city and the students' reading scores ranked the lowest. The fight for community control and empowerment in District 6 began in 1980 when the Community Association of Progressive Dominicans confronted the school board and superintendent to demand bilingual education and programs for recently arrived immigrant families. Over the years Dominicans have gained a greater representation on the school board. Other subsequent gains have included the construction of additional public schools in the district and the appointment of a Dominican principal to head one of the community high schools. The recent, successful campaign to redress district lines in Washington Heights (District 10) is a striking example of the "coming of age" of Dominican community associations and of the collaboration between Dominicans and other area Latinos (Graham 1996). Facilitated by federal legislation aimed at redressing the old practice of dividing geographic concentrations of ethnic groups to dilute their political influence, the newly created "Dominican district" reflects its Dominican majority and has created a jurisdiction in which Dominican officials might be more readily elected.

The Dominican presence clearly is felt in the economic life of Washington Heights, where Dominican-owned businesses are burgeoning. One recent study of this neighborhood estimated between 1,500 and 2,000 visible Dominicanowned enterprises (Guarnizo 1992). These include scores of neighborhood bodegas, restaurants specializing in comida criolla (Dominican cuisine), travel agencies, money transfer agencies, and non-medallion "gypsy" cab services. A study found an average of 12 Dominican businesses per block between $157^{\text {th }}$ and $191^{\text {st }}$ Streets in upper Manhattan (Mahler 1989, 89). These ethnic-oriented business establishments help ease the transition between "here" and "there."

New York based organizations, further, have mobilized Dominicans to affect politics in the Dominican domestic sphere "there." As part of Dominican politics, it has become a tradition that any candidate holding serious political aspirations has to come to proselytize in New York and that every Dominican political party has to have a chapter in the City. These political organizations, which include major branches of the country's two leading parties, the PRD (Partído Revolucionário Dominicano) and PLD (Partído de la Liberación Dominicana), hold a powerful role in the Dominican election process. In an article entitled "New York Dominicans Strongly Back Candidates on Island," published in the New York Times, 29 June 1996, PRD presidential candidate José Francisco Peña Gomez states in interview with Larry Rohter: "The part they [New York City-based party branches] play is absolutely decisive, especially in terms of

Encrucijada/Crossroads 1.1 (2003): 57-78 
campaign finances." In the same article, Beinvenido Pérez, a New York City resident who is the PLD's campaign chief in the United States, is quoted as agreeing: "The Dominican community abroad has tremendous economic weight and political prestige, so of course its influence is being felt." This attitude was enhanced by the 1994 political reforms, which allow for the principle of dual citizenship.

Similarly, Dominican organizations in the United States are involved in economic development programs in the Dominican Republic. Immigrants have formed transnational organizations aimed at improving conditions in their native towns and villages. The Miraflores Development Committee (MDC), a group of approximately 20 men and women from a small southern village in the Dominican Republic, serves as such an example (Levitt 1997). Between 1992 and 1994, this organization raised approximately $\$ 70,000$ to build an aqueduct and renovate the village school, health clinic, and community center. Construction of a funeral home and baseball stadium are currently underway. Immigrant Mirafloreños began meeting informally in the early 1970s. At first, these gatherings were purely social, but members soon decided to work toward improving conditions at home. They approached non-migrant leaders in Miraflores about forming a joint group; this has existed, in various incarnations, ever since.

This surge of Dominican formal associations is accompanied by the sustainability of traditional, informal associations. The Dominican "San" serves as such an example. A San is an alternative means of credit and involves a limited number of participants who agree to make regular contributions to a fund that is given to each contributor in rotation, either in whole or part (Sassen-Koob 1987, 283) "San" is frequently used to finance those social rituals, i.e., weddings and funerals, which require large, single outlays of money. The "San" is used by Dominicans in New York City to finance various kinds of activities, a fact that may explain at least in part the rising number of small shop owners in the community. Further, it is used to finance the documents, travel, and initial settlement cost involved in getting to New York. Such an association is a significant structure of a "rural" society that produces a support system for emigration to a foreign and urban milieu.

Despite the Dominican proclivity to form and maintain networks and associations, in comparison to other Americans, they have experienced a fair share of economic hardship. Substantial social capital has not been enough to sustain economic progress. Dominicans have been disadvantaged by their concentration in low-waged occupations as well as their comparatively low levels of education. While in 1990 virtually half (49 percent) of all Dominicans in the New York labor force were employed as operatives, laborers, and personal service workers, among other large Caribbean immigrant groups, only 37 percent 
of the Jamaicans, 45 percent of the Haitians, and 40 percent of the Cubans were concentrated in such low-wage occupations (Grassmuck and Pessar.1996, 283). One reason for the relatively low occupational attainment of Dominicans is their relatively low levels of education. According to Grasmuck and Pessar, more than 60 percent of Dominicans over 25 have not completed high school compared to 34 percent of the Jamaicans, 35 percent of the Haitians, and 53 percent of the Cubans residing in New York City in 1990.

Compounding Dominicans' labor-market and educational disadvantages is evidence of considerable family disorganization. More than half of all Dominican households are female-headed and more than half of these are living below the poverty line. Struggles that may have begun as courageous acts by women for empowerment all too frequently have ended in impoverishment. This is sadly attested to by the fact that in 1990, 52.4 percent of Dominican female householders were living below the poverty line, in comparison to 19.1 percent of the married Dominican householders (Grassmuck and Pessar 1996, 286).

Moreover, racial discrimination is yet another serious obstacle confronting Dominican immigrants. In the 1990 census the vast majority of Dominicans in New York City identified themselves as either mulatto, specified as "other" (50 percent) or "black" (25 percent). Skin color is a very significant predictor of poverty among Dominicans, with black and mulatto Dominicans having strikingly higher poverty levels than white Dominicans (Grassmuck and Pessar 1996, 185). Experiences of being "confused" with African Americans and being discriminated against because of their dark pigmentation are especially unsettling for Dominican immigrants who come from a society where to be partly white is to be non-black.

In order to evaluate the potential trends in Dominican social capital formation, it is important to address the patterns found amongst other more established Latino immigrant groups in the United States, specifically Cubans and Mexicans. ${ }^{5}$ As demonstrated by the Dominican experience, the social world of immigrants in the United States is one thoroughly permeated by kinship and ethnic ties. Portes (1985) conducted a study on "successful" immigrant adaptation by Cuban political refugees and Mexican migrants in the 1970s. According to this study, at the moment of arrival in 1973, Cuban exiles had an average of ten relatives and friends awaiting them; Mexicans had an average of four kin and friends expecting them.

Unlike primary social relationships, patterns of formal organizational membership differed markedly between the two samples. About two-thirds of the Cubans and Mexicans did not belong to any organizations in 1976. In 1979, the situation remained unchanged for the Mexicans, but more than half of the Cubans now belonged to at least one organization. ${ }^{6}$ Despite these differences, the two groups are similar in the ethnic character of the organizations they join. The process of occupational and income attainment among Cuban political refugees

Encrucijada/Crossroads 1.1 (2003): 57-78 
was significantly influenced by the availability of an ethnically organized enclave; as descendants of a long-entrenched system of working-class migration, Mexican immigrants do not have an enclave option. Portes $(1985,333)$ further concludes:

Early adaptation $[\ldots]$ is not a matter of simply moving from the ethnic community into the broader society. It is instead a simultaneous and complementary process whereby ckolsaic ties are emphasized precisely as individuals attempt to gain entry into institutions of the host society and move up its different social hierarchies. Rather than abandoning personal relationships within their own groups, immigrants who have moved farthest into the outside world seem to rely more heavily on such bonds. Ethnic resilience, not assimilation, is the theoretical perspective more congruent with this interpretation.

In terms of personal traits, Mexicans and Cubans were more similar than different at the moment of arrival, with both tracing their origins to populations of modest education and economic means in their countries of origin. The factors that differed and that accounted for the manifold differences in their attainment processes were the social contexts that the groups encountered in the United States.

The Dominican immigrant community - like the Mexican case-faces an economic refugee status. Yet, unlike Mexicans, Dominican migrants are a new cultural group in the Untied States. Despite their social, educational, and regional heterogeneity and precisely because of their shared migratory and social experiences in the United States and Dominican Republic, they have become a group whose territory is a borderless, transnational space. They-unlike Cubans-are here and there and in between. Dominican migrants will continue a process of socio-cultural accommodation (rather than assimilation) and economic articulation (rather than adaptation) in both North America and their native land attempting to fabricate positive social contexts. How this group democratizes and prospers internally and socially depends on their ability to mobilize and create social cohesiveness based on ethnic bonds.

\section{Conclusion and Discussion: The Case in Light of the Model}

In this work how one specific immigrant group develops and uses social capital, and how such capital affects their potential to mobilize as an ethnic community is analyzed. Some of the principal socio-economic and political characteristics of the Dominican migration to the United States, and the development of community networks and associations of Dominicans residing in New York City are described. An economic and social profile of the Dominican immigrant community was presented and the extent to which this group has 
organized and, in effect, generated social capital in all its degrees was evaluated. The purpose of this work is to emphasize the importance of social and civic engagement on the economic development and democratization of an immigrant community using the Putnam model. Because different social contexts and different dynamics may affect different sets of immigrants and their offspring, the concepts of social capital and social integration require more elaboration and refinement.

If ethnic communities are interpreted in terms of social capital, it becomes possible to suggest a mechanism by which community-based support systems and positive cultural orientations can provide an adaptive advantage for immigrants and their offspring in their struggle to achieve their goals in American society. This mechanism is never stagnant; it constantly accommodates changes in the process of immigration. Social capital should thus be treated as "a process," rather than as a concrete object, that facilitates access to benefits and resources that best suit the goals of specific immigrant groups (Fernández-Kelly 1985). However, strong social capital formation does not guarantee an immigrant community's successful integration to the receiving nation's economic and political mainstream.

Dominicans are forging a new ethnic community in New York-one that by all signs will keep growing as conditions in the Dominican Republic continue to deteriorate. Over the past decades, this search for a better life has rewarded one segment of the community with economic advancement; many of these have been professionals and entrepreneurs, who have either returned home permanently or have constructed binational lives. The majority of Dominican New Yorkers, however, have had to settle for far less. They have confronted declining local opportunities for stable, well-paying employment, severe over-crowding within low-income neighborhoods, deteriorating public services, and a mainstream America that is growing ever more intolerant of poor, non-white immigrants and their second-generation offspring.

Overall, social capital furnishes migrant individuals and families with resources beyond their individual reach by creating connections and support. However, it is important to note that such capital can also generate some limits to the possibilities of success of an immigrant group. Because of obligations and expectations of solidarity that are too demanding, social capital can thus become negative social capital. One consequence of negative social capital is the strengthening of in-group social capital among migrants, limiting the potential for solidarity with other ethnic groups (Pessar 1997). This phenomenon has yet to be evaluated in the Dominican community.

For a variety of noted reasons, generally life is easier in a community blessed with a substantial stock of social capital. In the first place, networks of civic engagement foster sturdy norms of generalized reciprocity and encourage

Encrucijada/Crossroads 1.1 (2003): 57-78 
the emergence of social trust. Such networks facilitate coordination and communication, amplify reputations, and thus allow dilemmas of collective action to be resolved. At the same time, networks of civic engagement embody past success at collaboration, which can serve as a cultural template for future collaboration.

The surge in Dominican organizations means that Dominicans are trusting each other and forming an ethnic minority identity in the United States. The Dominican immigrant community is growing and maturing, and, thus, movements to accommodate this phenomenon have surged in the form of organizations and associations based on a common ethnicity. The unification of the Dominican identity must be seen as a major step towards greater participation in local and national political processes. Moreover, the sense of an emerging group identity has generated the foundation for massive political mobilization. Calling for such ethnic politics should not frighten the rest of the United States. Portes and Rumbaut (1990, 142) write:

What held [the USA] together then and continues to do so today is not cultural homogeneity, but the strength of its political institutions and the durable framework that they offered for the process of ethnic reaffirmation to play itself out. Defense of their own particular interests-defined along ethnic lines-was the school in which many immigrants and their descendants learned to identify with the interests of the nation as a whole. With different actors and in new languages, the process continues today.

Furthermore, it is important to acknowledge that Dominicans have their way of "doing" civic life, informally. Academics and policy-makers alike must recognize that immigrant communities are not voids to be organized and filled by the more knowledgeable; they are well developed, complex, and sophisticated organisms that demand to be understood on their own terms - or they will not cooperate. Voluntary associations and organized public events are not the primary expression of the migrants' transnational identity, but rather the informal practices of everyday life. Through popular culture, especially through spoken language, music, food, and religion, Dominicans celebrate their sense of belonging to a group generating transnational social capital.

Originally, the concept of social capital was nothing more than an elegant term to call attention to the possible individual and family benefits of sociability. That usage is entirely compatible with a nuanced understanding of the pros and cons of groups and communities. The call for higher social capital as a solution to the problems of the inner-city misdiagnoses the problem and can lead to both a waste of resources and new frustrations. As Dominicans demonstrate, it is not the lack of social capital, but the lack of economic resources and opportunities that 
underlies the plight of impoverished urban groups, in particular new immigrant communities.

Encrucijada/Crossroads 1.1 (2003): 57-78 


\section{Notes}

${ }^{1}$ During the same period, tens of thousands of Dominicans have also emigrated to some European and Latin American countries, such as Spain, Holland, Switzerland, and Venezuela.

${ }^{2}$ The names of people have been changed to protect the anonymity of the informants.

${ }^{3}$ This contrasts with the traditional European "export" countries which created institutions to facilitate the exchange of resources and information between immigrant and country of origin.

${ }^{4}$ Ceará, Margarita. Interview by author, 4 April 1998.

${ }^{5}$ Puerto Ricans are not addressed due to their particular 'citizen' status in the United States.

${ }^{6}$ Churches were the preferred form of organizational membership in both groups. 


\section{Works Cited}

Baez Evertsz, F. and F. D'Oleo Ramirez. 1986. La emigración de dominicanos a Estados Unidos: Determinantes socioeconómicos y consecuencias. Santo Domingo: Fundación Friedrich Ebert.

Bourdieu, Pierre and Loic Wacquant. 1992. An invitation to reflexive sociology. Chicago: University of Chicago Press.

Bray, D. 1987. The Dominican exodus: Origins, problems, solutions. In Caribbean exodus, edited by B. Levine. New York: Praeger.

Burt, Ronald. 1997. Contingent value of social capital. Administrative Science Quarterly 42 (2): 339-65.

Ceará, Margarita. 1988. Interview by author. 4 April.

Coleman, James. 1990. Foundations of social theory. Cambridge, MA: Belknap Press of Harvard University.

Fernandez-Kelly, M. Patricia. 1995. Social capital and cultural capital in the urban ghetto: Implications for the economic sociology of immigration. In Economic Sociology of Immigration, edited by Alejandro Portes. New York: Russell Sage Foundation.

Garrison, Vivian and Carol I. Weiss. 1987. Dominican family networks and United States immigration policy: A case study. In Caribbean life in New York City: Sociocultural dimensions. First published in International Migration Review 12, no. 2 (1979): 264-83.

Georges, E. 1984. Dominican diaspora: Putting down roots? Hispanic Monitor 1 (2): 6 .

---. 1987. A comment on Dominican ethnic associations. In Sutton and Chaney.

---. 1989. Participación política de una nueva población hispana. In Dominicanos ausentes: Cifras, políticas, condiciones sociales, edited by E. George. Santo Domingo: Fundación Friedrich Ebert, 1989.

Graham, Pamela. 1996. Nationality and political participation in the transnational context of Dominican migration. In Caribbean Circuits, edited by Patricia Pessar. New York: Center for Migration Studies.

Grasmuck, Sherri. and Patricia Pessar. 1991. Between two islands. Berkeley: University of California Press.

---. 1996. First and second-generation settlement of Dominicans in the U.S.: 1960-1990. In Origins and destinies: Immigration, race and ethnicity in America, edited by S. Pedraza and R. Rumbaut. Belmont, CA: Wadsworth Press.

Encrucijada/Crossroads 1.1 (2003): 57-78 
Guarnizo, Luis E. 1992. One Country in Two: Dominican-Owned Firms in New York and the Dominican Republic. Ph.D. diss., Johns Hopkins University.

---. 1994. Los Dominicanyorks: The making of a binational society. Annals, AAPSS 533: 70-86.

Gurak, D.T. 1982. Immigration history: Cubans, Dominicans, and Puerto Ricans. In Hispanics in New York: Religious, cultural and social experiences. Vol. 2. New York: Office of Pastoral Research, Archdiocese of New York.

Hendricks, Glen. 1974. The Dominican Diaspora: From the Dominican Republic to New York City-Villagers in transition. New York: Teachers College Press.

Hernández, Ramona and Francisco Rivera-Batiz. 1997. Dominican New Yorkers: A socioeconomic profile, 1997. New York: The CUNY Dominican Studies Institute.

Levitt, Peggy. 1997. Transnationalizing community development: The case of migration between Boston and the Dominican Republic. Nonprofit and Voluntary Sector Quarterly 26 (4): 509-526.

Linares, Guillermo. 1989. Dominicans in New York: Superando los obstáculos y adquiriendo poder: The struggle for community control in District 6. Centro Bulletin 2 (5): 78.

Mahler, Sarah. 1989. La dinámica de la legisalción en Nueva York: Un enfoque hacia los dominicanos. In George 1989.

Pessar, Patricia. 1987. The Dominicans: Women in the household and the garment industry. In New immigrants in New York, edited by Nancy Fomer. New York: Columbia University Press.

---. 1997. Dominicans: Forging an ethnic community in New York. In Beyond Black and White, edited by Maxine Seller and Lois Weiss. New York: SUNY.

Portes, Alejandro. 1985. Latin journey: Cuban and Mexican immigrants in the U.S. Berkeley: University of California Press.

Portes, Alejandro and Ruben G. Rumbaut. 1990. Immigrant America: A portrait. Berkeley: University of California Press.

Portes, Alejandro and Ramón Grosfoguel. 1994. Caribbean diasporas: Migration and ethnic communities. Annals, AAPSS 533: 60-69.

Putnam, Robert. 1993. Making democracy work: Civic traditions in modern Italy. Princeton: Princeton University Press.

---. 1995. Bowling alone: America's declining social capital. Journal of Democracy 6 (1): 65-78. 
Rohter, Larry. 1996. New York Dominicans strongly back candidates on island. New York Times, 29 June 1996.

Sassen-Koob, Saskia. 1987. Formal and informal associations: Dominicans and Colombians in New York. In Sutton and Chaney.

Sutton, Constance R. and Elsa M. Chaney, eds. 1984. Caribbean life in New York City: Sociocultural dimensions. New York: Center for Migration Studies of New York, Inc.

Youssef, Nadia H. 1982. The demographics of immigration. New York: Center for Migration Studies.

Encrucijada/Crossroads 1.1 (2003): 57-78 